\title{
Keanekaragaman Jenis Echinodermata pada Zona Intertidal di Pesisir Selatan Pulau Tidung Kecil Kepulauan Seribu DKI Jakarta
}

\author{
Mashudi Alamsyah $^{1 *}$, Martua Ferry Siburian ${ }^{1}$, Giry Marhento ${ }^{1}$ \\ ${ }^{1}$ Fakultas MIPA, Prodi Pendidikan Biologi, Universitas Indraprasta PGRI \\ *email: mashudi.alamsyah@gmail.com
}

\begin{tabular}{l} 
Article History \\
\hline Received: \\
02/11/2021 \\
Revised: \\
10/11/2021 \\
Accepted: \\
23/11/2021 \\
\\
Kata kunci: \\
Keanekaragaman \\
Echinodermata \\
Zona intertidal \\
Kepulauan Seribu
\end{tabular}

Key word: Diversity Echinoderms Intertidal zone Thousand Islands

\begin{abstract}
ABSTRAK
Tujuan penelitan ini adalah untuk mengetahui keanekaragaman dan jenis Echinodermata apa saja yang terdapat pada zona intertidal di pesisir pantai selatan Pulau Tidung Kecil Kepulauan Seribu. Metode penelitian yang digunakan untuk pengambilan sampel dalam penelitian ini yaitu menggunakan metode transek garis, sedangkan untuk pengumpulan data menggunakan teknik triangulasi (observasi, wawancara, dan dokumentasi). Analisis data dilakukan dengan cara menghitung kelimpahan jenis, indeks keanekaragaman, dan indeks keseragaman. Hasil penelitian ini ditemukan tiga kelas Echinodermata yang terdiri dari lima spesies dengan total 140 individu serta tersebar pada berbagai substrat pada ketiga stasiun. Analisis indeks keanekaragaman pada stasiun $\mathrm{I}=0.674$, stasiun $\mathrm{II}=1.087$ dan stasiun $\mathrm{III}=0.825$, sementara indeks kemerataan jenis pada stasiun $\mathrm{I}=0.166$, stasiun $\mathrm{II}=0.310$, dan stasiun III $=0.210$ dan komposisi jumlah individu dari masing masing spesies jenis ketiga stasiun berkisar antara 99.95$100 \%$.
\end{abstract}

\section{ABSTRACT}

The purpose of this study was to determine the diversity and types of echinoderms found in the intertidal zone on the southern coast of Tidung Kecil Island, the Thousand Islands. The research method used for sampling in this study is using the line transect method, while for data collection using triangulation techniques (observation, interviews and documentation). Data analysis was carried out by calculating species abundance, diversity index, and uniformity index. The results of this study found 3 classes of Echinoderms consisting of 5 species with a total of 140 individuals and spread on various substrates at the three stations. Analysis of the diversity index at station $I=0.674$, station $I I=1.087$ and station $I I I=0.825$, while the species evenness index at station $I=0.166$, station $I I=0.310$, and station $I I I=0.210$ and the composition of the number of individuals from each species of the three stations ranged from 99.95-100\%.
\end{abstract}

Copyright @ 2022 LPPM Universitas Indraprasta PGRI. All Right Reserved

\section{PENDAHULUAN}

Negara Kesatuan Republik Indonesia mempunyai banyak pulau besar dan pulau kecil dengan luas total laut sekitar 5 juta $\mathrm{km}^{2}$ dan memiliki garis pantai sepanjang $108.920 \mathrm{~km}$ (Suharsono, 2014). Oleh karena itu Indonesia memiliki keanekaragaman laut yang tinggi dan menjadi salah satu wilayah marine mega biodiversity terbesar di dunia (Setiawan, 2018). Salah satu wilayah perairan Indonesia yang kaya akan variasi hewan laut khususnya invertebrata adalah perairan kepulauan seribu di DKI Jakarta.
Berdasarkan observasi lapangan yang telah dilakukan di zona intertidal di kepulauan seribu khususnya di pesisir selatan pulau tidung kecil ditemukan berbagai jenis hewan invertebrata yang termasuk ke dalam filum echinodermata, diantaranya adalah bintang laut, bulu babi, bintang ular, dan timun laut yang memiliki kesamaan ciri yaitu tubuh yang berduri. Echinodermata merupakan salah satu filum yang berasal dari hewan-hewan invertebrata atau hewan yang tidak bertulang belakang. Echinodermata berasal dari dua kata yaitu echinos yang berarti duri dan derma yang berarti kulit, sehingga hewan ini disebut hewan yang kulitnya berduri dalam Bahasa Yunani 
(Huda, 2017). Filum Echinodermata memiliki lima kelas yaitu kelas Asteroidea yang dikenal sebagai bintang laut, yaitu kelas Echinoidea atau landak laut, kelas Ophiuroidea atau bintang ular, kelas Crinoidea atau lili laut, dan kelas Holothuroidea atau teripang (Hartati, 2018). Seluruh hewan Echinodermata mempunyai bentuk bilateral simetris ketika larva dan radial simetris setelah dewasa. Hewan ini memiliki zat kapur di endoskeletonnya dan mempunyai sistem vaskular, juga kemampuan regenerasi pada bagian tubuh yang hilang atau rusak (Schories \& Kohlberg, 2016).

Echinodermata juga menjadi salah satu simbol laut dikarenakan Echinodermata merupakan invertebrata laut yang bersifat sternohalin/salinitas dan jumlahnya terbatas pada kemampuan osmoregulasi, sehingga Echinodermata sebagian besar dibatasi hanya di lingkungan laut (Clark \& Rowe, 1971). Secara ekologis, Echinodermata dikenal sebagai detritus perairan karena Echinodermata memakan 'sampah' organik, sehingga Echinodermata juga berperan sebagai komponen dalam rantai makanan yang ada di laut (Pallo, 2001). Pada jaring-jaring makanan, Filum Echinodermata juga dikenal sebagai makanan lezat dan sebagai souvenir pada perdagangan hiasan akuarium. Namun, berdasarkan hasil wawancara warga sekitar kepulauan seribu, Echinodermata yang terdapat di pesisir pantai Pulau Tidung Kecil masih minim dimanfaatkan dengan baik dan hanya beberapa spesies saja yangdimanfaatkan (Jambo, 2021).

Echinodermata dapat hidup di wilayah zona intertidal atau wilayah pasang surut. Zona intertidal merupakan salah satu bagian dari zona litoral (Michael, 1984). Zona intertidal merupakan zona yang dibatasi oleh garis pasang surut air laut, sekaligus sebagai zona yang paling sempit diantara zonasi laut yang lain (Nybakken, 1992). Zona intertidal memiliki habitat yang lebih beragam dibanding zona laut yang lain, contohnya adalah area lamun, makroalga, batu karang, dan batu keras. Terdapat beberapa faktor utama yang memengaruhi kelimpahan Echinodermata pada zona pasang surut. Faktor tersebut yaitu ada atau tidaknya makanan, kondisi substrat, dan parameter lingkungan lainnya (Widiansyah et al., 2016).
Zona intertidal pesisir pantai pulau tidung kecil merupakan zona dengan karakteristik habitat yang cocok untuk kehidupan Echinodermata, karena terdapat beberapa substrat seperti lamun, bebatuan, pecahan karang, dan pasir. Namun, data ataupun publikasi tentang keanekaragaman spesies tersebut belum diketahui secara pasti. Terbatasnya informasi mengenai Echinodermata di pantai ini menyebabkan perlu dilakukannya riset lanjutan untuk memberikan informasi mengenai keanekaragaman Filum Echinodermata, berdasarkan indeks keanekaragaman dan indeks kemerataan. Oleh karena itu, penelitian ini bertujuan untuk mengetahui keanekaragaman Echinodermata di pesisir selatan pantai pulau Tidung Kecil kepulauan Seribu DKI Jakarta.

\section{METODE PENELITIAN}

Penelitian ini dilakukan melalui pengambilan sampel dengan cara observasi lapangan menggunakan metode Line Transect pada kondisi alam yang artinya data yang dikumpulkan berdasarkan kondisi nyata saat observasi, sedangkan analisis data yang diperoleh dilakukan dengan indeks keanekaragaman, kemerataan dan kelimpahan Echidodermata yang hidup di zona intertidal (Triacha, 2021). Prosedur penelitian meliputi studi kepustakaan dan pengumpulan data, survei dan penyiapan instrumen yang diperlukan untuk penelitian ini. Alat dan bahan yang digunakan dalam penelitian ini adalah alat ukur, stasioner, tali, kamera tahan air, kayu, pipa 2 meter, dan timer. Studi pendahuluan dilakukan untuk menentukan lokasi penelitian serta ukuran daerah pengambilan sampel. Lokasi ditentukan y menggunakan metode random terpilih berdasarkan kriteria lokasi dan ditetapkan di wilayah pesisir selatan pantai pulau tidung kecil Kepulauan Seribu. Peneliti juga melakukan beberapa wawancara untuk mendapatkan data tentang jenis-jenis Echinodermata yang hidup di lokasi, prosedur ini juga didukung dengan survei dan dokumentasi. Pengambilan sampel dilakukan dengan metode Line Transect untuk mengetahui indeks keanekaragaman, kemerataan, dan kelimpahan Echinodermata pada setiap stasiun penelitian. 

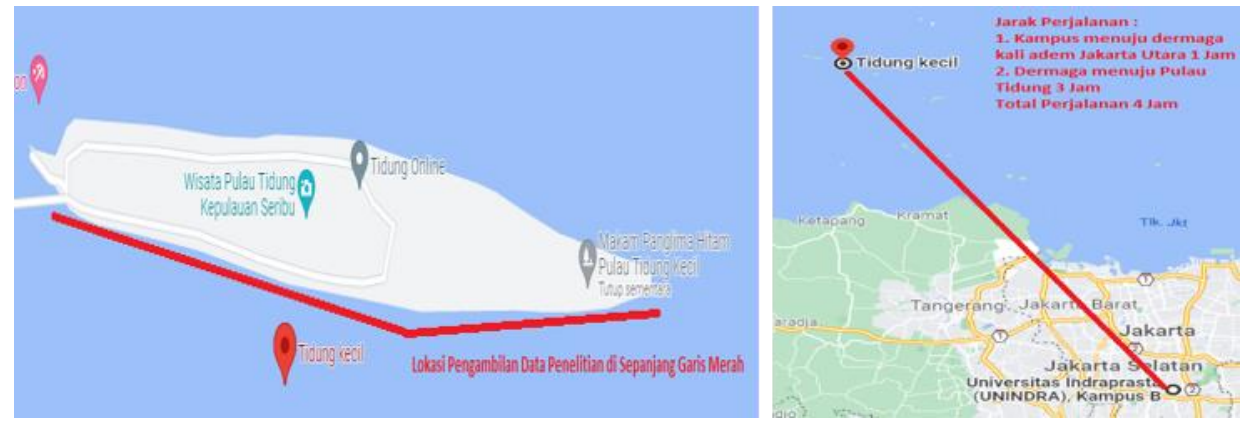

Gambar 1. Lokasi penelitian dan jarak penelitian

Sumber: Google Maps

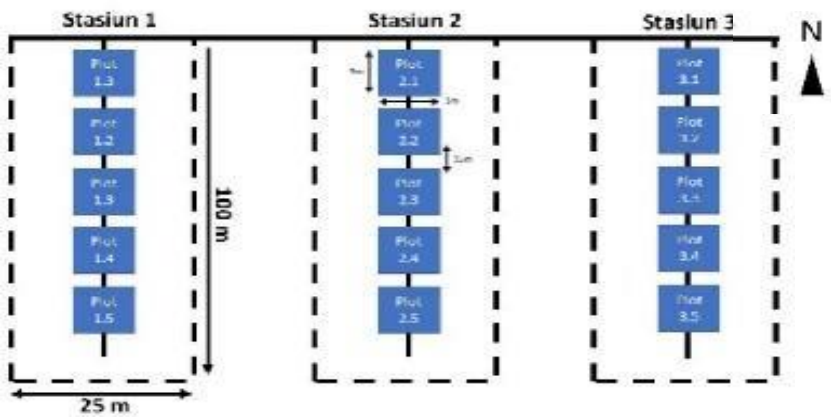

Gambar 3. Desain Line Transect

Tabel 1. Jenis Echinodermata

\begin{tabular}{|c|c|c|c|c|c|}
\hline \multirow{2}{*}{ No } & \multirow{2}{*}{ Spesies } & \multicolumn{3}{|c|}{ Transek } & \multirow[t]{2}{*}{ Jumlah } \\
\hline & & I & II & III & \\
\hline 1 & & & & & \\
\hline 2 & & & & & \\
\hline
\end{tabular}

Keanekaragaman jenis Echinodermata di dianalisis dalam indeks keanekaragaman, indeks kemerataan, dan komposisi spesies yang merupakan indeks keanekaragaman spesies.

Keterangan:

$$
H^{\prime}=-\sum \text { pi ln pi }
$$

H' : Indeks keanekaragaman Shanon-wienner

$\mathrm{Pi} \quad$ : Perbandingan jumlah individu spesies ke-i dengan jumlah individu total (ni/N)

Ni : Jumlah individu ke-i

$\mathrm{N} \quad$ : Jumlah total individu

Persyaratan:

$\mathrm{H}^{\prime}>1 \quad$ : Komunitas biota tidak stabil

$1<\mathrm{H}^{\prime}<3 \quad$ : Stabilitas komunitas biota sedang

$\mathrm{H}^{\prime}>3$ : Stabilitas komunitas biota dalam

kondisi baik

Sedangkan untuk komposisi spesies dihitung dengan rumus sebagai berikut:

$$
P=\frac{N i}{N} \times 100 \%
$$

Keterangan:

$P \quad=$ Tipe komposisi (\%)

$\mathrm{Ni} \quad=$ Jumlah individu tiap tipe

$N=$ Jumlah individu pada keseluruhan tipe

Indeks Kemerataan jenis Echinodermata di setiap habitat.

$$
E=\frac{H^{\prime}}{L n S}
$$

Keterangan:

$$
\begin{array}{ll}
\mathrm{E} & =\text { Indeks kemerataan } \\
\mathrm{H} & \quad=\text { Keanekaragaman spesies } \\
\mathrm{S} & =\text { Jumlah total spesies }
\end{array}
$$

Estimasi skor E antara 0 dan 1, skor 1 menggambarkan suatu kondisi dimana semua individu tiap spesies tersebar merata (Fachrul, 2006).

\section{HASIL DAN PEMBAHASAN}

Berdasarkan hasil penelitian dapat diketahui bahwa ketiga stasiun memiliki indeks keanekaragaman yang berbeda. Indeks keanekaragaman, ketiga stasiun tersebut termasuk dalam kriteria keanekaragaman dan produktivitas rendah yang menyebabkan ekosistem menjadi tidak stabil. Jenis Echinodermata yang ditemukan di setiap stasiun berbeda jumlahnya dan termasuk ke dalam kelas Asteroidea, Holothuroidea, dan Echinodiae. Indeks kenaekaragaman pada masing masing stasiun ditampilkan pada Tabel 2. 
Tabel 2. Jenis dan jumlah individu Echinodermata yang ditemukan pada tiga stasiun di zona intertidal

\begin{tabular}{|c|c|c|c|c|c|}
\hline \multirow{2}{*}{ No } & \multirow{2}{*}{ Spesies } & \multicolumn{3}{|c|}{ Transek } & \multirow{2}{*}{ Jumlah } \\
\hline & & I & II & III & \\
\hline \multirow[t]{3}{*}{1} & \multirow{3}{*}{$\begin{array}{l}\text { Diadema setosum } \\
\text { Tripeneustes } \\
\text { gratilla } \\
\text { Echinocardium } \\
\text { cordatum }\end{array}$} & 40 & 20 & 35 & 75 \\
\hline & & 1 & 2 & 1 & 4 \\
\hline & & - & 1 & 1 & 2 \\
\hline 2 & $\begin{array}{l}\text { Culcita } \\
\text { novaeguineae }\end{array}$ & - & 2 & 1 & 3 \\
\hline 3 & $\begin{array}{l}\text { Holothuroidea } \\
\text { leucospilota }\end{array}$ & 16 & 8 & 12 & 36 \\
\hline & Total & 57 & 33 & 50 & 140 \\
\hline & Total Spesies & 3 & 5 & 5 & 13 \\
\hline
\end{tabular}

Terdapat 3 kelas Echinodermata yang ditemukan di stasiun I terdiri dari kelas Asteroidea, kelas Holothuroidea, dan kelas Echinodea dengan jumlah total sebanyak 57 individu. Pada stasiun I didominasi oleh Echinoidea. Berdasarkan habitat dan sebaran kelas Echinoidea khususnya genus Diadema, genus ini umumnya menempati daerah berpasir tempat tumbuhnya alga. Pada stasiun II ditemukan 33 individu yang termasuk ke dalam 5 kelas; 3 jenis dari kelas Echinodea, 1 jenis dari kelas Asteroidea, dan 1 jenis dari kelas Holohturidea. Stasiun II memiliki substrat yang didominasi oleh Echinodea dan Holoturidea dengan spesies Diadema stosum dan Holotuhridea leucosplito. Sebanyak 50 individu dari 5 kelas ditemukan di stasiun III. Kelas tersebut adalah 3 jenis dari kelas Echinodea, 1 jenis dari kelas Asteroidea, dan 1 jenis dari kelas Holohturidea. Jenis tersebut diidentifikasi sebagai Culcita novageuneae, Holothuria leucospilota, Diasema setosum, Tripeneusstes gratilla dan Echinocardium cordatum. Spesies Holothuroidea leucospilota ditemukan di setiap transek meskipun ada perbedaan jumlah, sedangkan Asteroidea hanya ditemukan sedikit di setiap transek. Indeks kenakaragaman pada Tabel 3 menggambarkan apakah Echinodermata memiliki tingkat keanekaragaman di zona intertidal serta memberikan informasi tentang jenis-jenis Echinodermata yang hidup di lokasi penelitian.

Tabel 3. Indeks keanekaragaman pada stasiun I, II, dan III

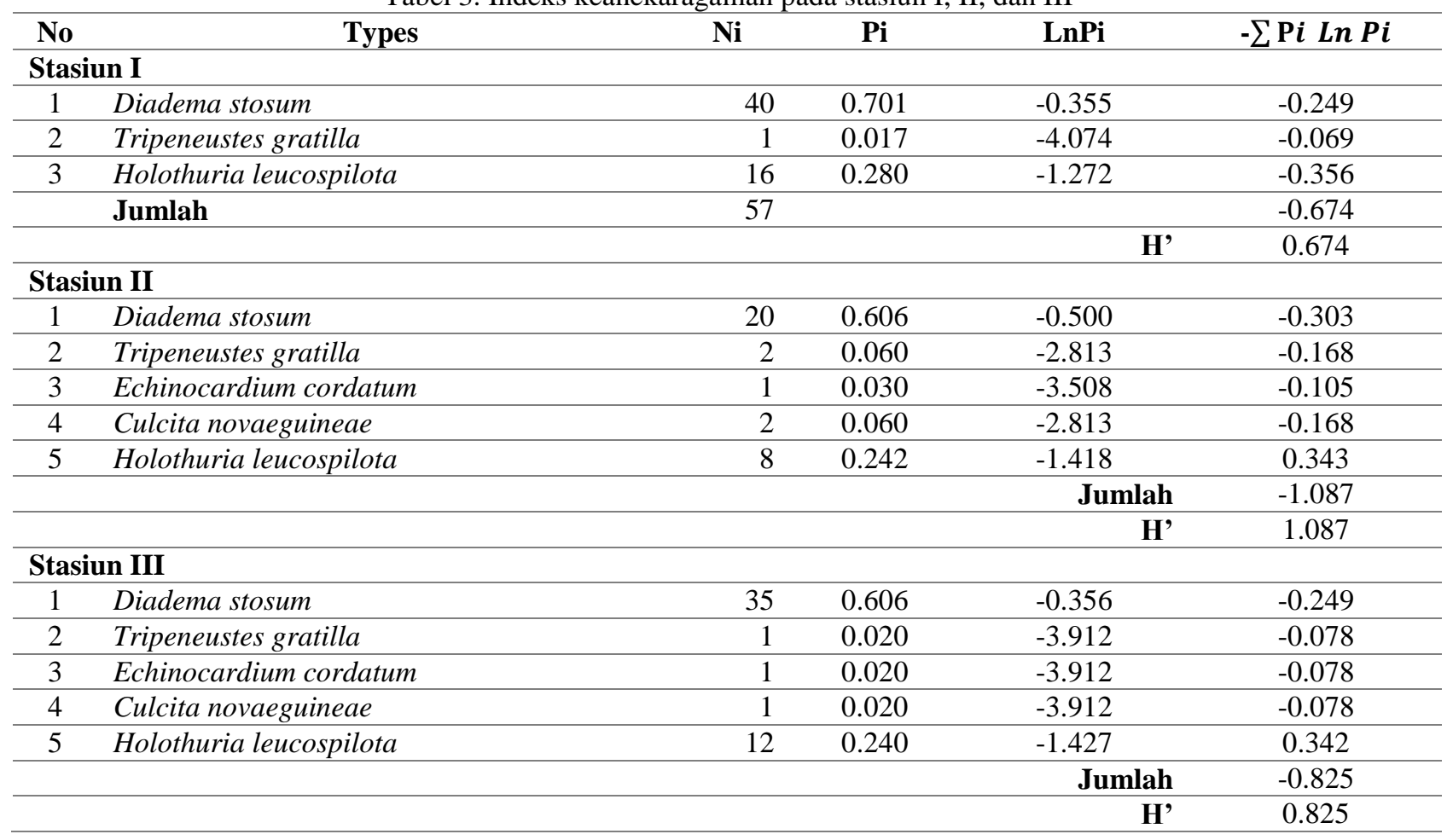

Berdasarkan Tabel 3 dapat dilihat bahwa indeks keanekaragaman Echinodermata yang terdapat pada stasiun I adalah $H^{\prime}=0.674$, stasiun II adalah $H^{\prime}=1.087$ dan stasiun III adalah $H^{\prime}=0.825$. Disimpulkan bahwa indeks keanekaragaman stasiun I adalah yang terendah di bandingkan stasiun II dan stasiun III. Hasil perhitungan indeks keanekaragaman ditunjukkan pada Gambar 4. 


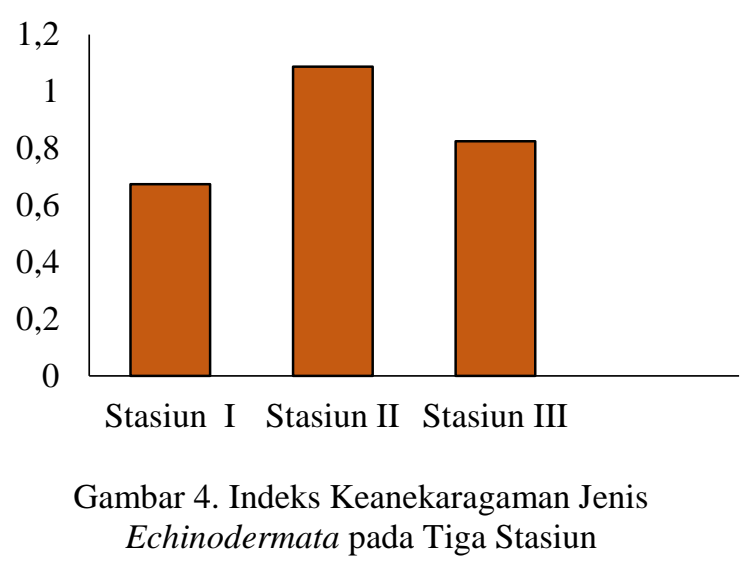

Perhitungan komposisi jenis Echinodermata menunjukkan bahwa pada Stasiun I memiliki persentase Diadema setosum (70.10\%), Tripeneustes gratilla 1.70\%, Holothuroidea leulospilota $28.07 \%$. Stasiun II didominasi oleh kelas Echinoidea, dengan nilai $60.60 \%$, spesies Holothuroidea leulospilota sebesar $24.20 \%$ dan spesies Culcita novaeguineae dengan sebesar $6.06 \%$. Stasiun III didominasi oleh spesies Diadema setosum dengan indeks $70.00 \%$ dan kelas Holothuroidea skor indeks $24.00 \%$. Perbandingan komposisi jenis pada setiap stasiun dapat dilihat pada Gambar 5.
Tabel 4. Komposisi jenis Echinodermata pada stasiun I, II, dan III

\begin{tabular}{|c|c|c|c|}
\hline No & Jenis & Jumlah & $\begin{array}{c}\text { Kelimpahan } \\
(\%)\end{array}$ \\
\hline \multicolumn{4}{|c|}{ Stasiun I } \\
\hline 1 & Diadema stosum & 40 & 70.10 \\
\hline 2 & $\begin{array}{l}\text { Tripeneustes } \\
\text { gratilla }\end{array}$ & 1 & 1.70 \\
\hline 3 & $\begin{array}{l}\text { Holothuria } \\
\text { leucospilota }\end{array}$ & 16 & 28.07 \\
\hline & Jumlah & 57 & 99.87 \\
\hline \multicolumn{4}{|c|}{ Stasiun II } \\
\hline 1 & Diadema stosum & 20 & 60.60 \\
\hline 2 & $\begin{array}{l}\text { Tripeneustes } \\
\text { gratilla }\end{array}$ & 2 & 6.06 \\
\hline 3 & $\begin{array}{l}\text { Echinocardium } \\
\text { cordatum }\end{array}$ & 1 & 3.03 \\
\hline 4 & $\begin{array}{l}\text { Culcita } \\
\text { novaeguineae }\end{array}$ & 2 & 6.06 \\
\hline 5 & $\begin{array}{l}\text { Holothuria } \\
\text { leucospilota }\end{array}$ & 8 & 24.20 \\
\hline & Jumlah & 33 & 99.95 \\
\hline \multicolumn{4}{|c|}{ Stasiun III } \\
\hline 1 & Diadema stosum & 35 & 70 \\
\hline 2 & $\begin{array}{l}\text { Tripeneustes } \\
\text { gratilla }\end{array}$ & 1 & 2 \\
\hline 3 & $\begin{array}{l}\text { Echinocardium } \\
\text { cordatum }\end{array}$ & 1 & 2 \\
\hline 4 & $\begin{array}{l}\text { Culcita } \\
\text { novaeguineae }\end{array}$ & 1 & 2 \\
\hline 5 & $\begin{array}{l}\text { Holothuria } \\
\text { leucospilota }\end{array}$ & 12 & 24 \\
\hline & Jumlah & 50 & 100 \\
\hline
\end{tabular}

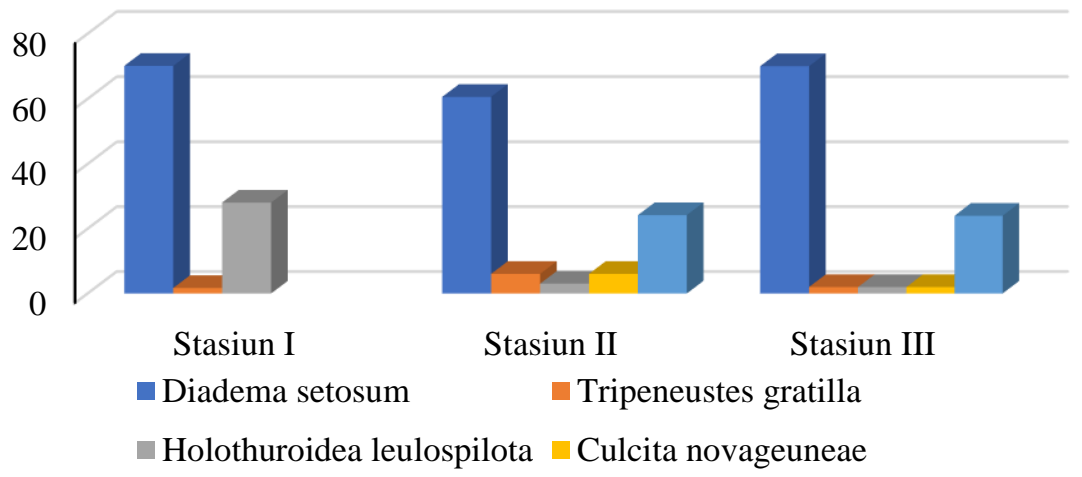

Gambar 5. Kelimpahan spesies Echinodermata di tiga stasiun 
Tabel 5. Indeks kemerataan di Stasiun I, II, dan III

\begin{tabular}{cccc}
\hline No & Stasiun & $\begin{array}{c}\text { Jumlah } \\
\text { Spesies } \\
\left(\mathbf{H}^{\prime}\right)\end{array}$ & $\begin{array}{c}\text { Indeks } \\
\text { Kemerataan }(\boldsymbol{E})\end{array}$ \\
\hline 1 & Stasiun I & 57 & 0.166 \\
\hline 2 & Stasiun II & 33 & 0.310 \\
\hline 3 & Stasiun III & 50 & 0.210 \\
\hline & Jumlah $(s)$ & 140 & \\
\hline
\end{tabular}

Indeks kemerataan ditunjukkan pada Gambar 6.

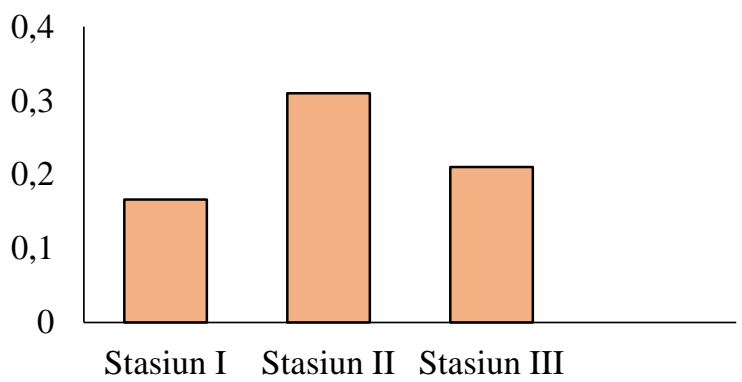

Gambar 6. Kemerataan stasiun I, II, III

Berdasarkan Tabel 5 dan Gambar 6, nilai indeks kemerataan stasiun I sebesar 0.166, stasiun II sebesar 0.310, sedangkan stasiun III sebesar 0.210. Jika indeks kemerataan suatu komunitas adalah 0.6-0.8, maka dapat disimpulkan bahwa jumlah individu pada setiap spesies komunitas tersebar merata. Berdasarkan kriteria tersebut dapat dikatakan bahwa penyebaran Echinodermata di Stasiun I, II, dan III tidak merata.

Tabel 6. Hasil perhitungan data

\begin{tabular}{cccc}
\hline Indeks & \multicolumn{3}{c}{ Transek } \\
\cline { 2 - 4 } & I & II & III \\
\hline H'(Keanekaragaman $^{\text {Spesies) }}$ & 0.674 & 1.087 & 0.825 \\
\hline $\begin{array}{c}\text { P (Kelimpahan } \\
\text { Spesies) }\end{array}$ & $99.87 \%$ & $99.95 \%$ & $100 \%$ \\
\hline $\begin{array}{c}\text { E (Kemerataan } \\
\text { Spesies) }\end{array}$ & 0.166 & 0.310 & 0.210 \\
\hline
\end{tabular}

\section{KESIMPULAN}

Ada 5 spesies Echinodermata dari tiga kelas Holothuroidea, Echinoidea dan Asteroidea dengan jumlah total 140 individu yang ditemukan di berbagai substrat zona Intertidal. 75 individu teridentifikasi sebagai spesies Diadema setosum, Tripeneustes gratilla, Echinocardium cordatum, sedangkan dari kelas Holothuroidea peneliti menemukan 36 individu dalam 1 spesies, Holothuroidea leucospilota. Setiap stasiun memiliki indeks keanekaragaman yang berbeda, stasiun I adalah $\mathrm{H}^{\prime}=0.674$, stasiun II adalah $\mathrm{H}^{\prime}=1.087$ dan stasiun III adalah $\mathrm{H}^{\prime}=0.82$. Berdasarkan indeks skoring tersebut, stasiun I tergolong keanekaragaman rendah sedangkan stasiun II dan III memiliki tingkat keanekaragaman sedang.

Sedangkan berdasarkan indeks kelimpahan, stasiun III memiliki skor tertinggi dibandingkan stasiun I dan II. Hal ini dapat terjadi karena stasiun III memiliki substrat berbatu, berpasir dengan banyak terumbu karang sebagai habitat potensial bagi Echinodermata. Spesies Diadema stosum dominan di stasiun III. Indeks kemerataan jenis pada stasiun I sebesar 0.166, stasiun II sebesar 0.310 dan stasiun III sebesar 0.210. Jenis Echinodermata yang ditemukan tersebar merata di setiap stasiun. Jumlah Echinodermata terbanyak berasal dari kelas Echinoidea sedangkan spesies yang paling dominan ditemukan di setiap stasiun adalah Diadema setosum.

Peneliti menyarankan untuk penelitian lebih lanjut tentang keanekaragaman Echinodermata agar dapat memberikan informasi yang bermanfaat bagi masyarakat terutama dalam pengelolaan dan pemanfaatan pantai tersebut. Di sisi lain, peneliti berharap pengawasan dan pengendalian yang serius terus dilakukan di kawasan pesisir selatan pantai pulau tidung kecil kepulauan seribu DKI Jakarta.

\section{DAFTAR PUSTAKA}

Clark A. M., \& Rowe, F. E. W. (1971). Monograph of Shallow Water Indo-West Pasific Echinoderms. Trustees of the British Museum (Natural History): London.

Fachrul. (2006). Metode Sampling Bioekologi. Bumi Aksara: Jakarta.

Hartati, R., Meirawati, E., Redjeki, S., Riniatsih, I., \& Mahendrajaya, R. T. (2018). Jenis-jenis bintang laut dan bulu babi (Asteroidea, Echinoidea: Echinodermata) di perairan Pulau Cilik, Kepulauan Karimunjawa. Jurnal Kelautan Tropis, 21(1), 4148. https://doi.org/10.14710/jkt.v21i1.2417.

Huda, M. A. I., Sudarmadji, S., \& Fajariyah, S. (2017). Keanekaragaman jenis Echinoidea di zona intertidal Pantai Jeding Taman Nasional Baluran. Jurnal Berkala Sainstek, 2(1), 61-65. https://doi.org/10.19184/bst.v5i2.5531.

Jambo, N. A., Kaligis, E. Y., Kumampung, D. R. H., Darwisito, S., Schaduw, J. N. W., \& Pratasik, S. B. (2021). Keanekaragaman dan kelimpahan filum Echinodermata pada zona 
intertidal Molas Kecamatan Bunaken Kota Manado. Jurnal Pesisir dan Laut Tropis, 9(2), 103-114. https://doi.org/10.35800/jplt.9.2.2021.35771.

Michael P. (1984). Metode Ekologi untuk Penyelidikan Lapangan dan Laboratorium. Universitas Indonesia Press: Jakarta.

Nybakken J. (1992). Biologi Laut, Suatu Pendekatan Biologi. Gramedia: Jakarta.

Pallo, B. C., \& Lewaherilla, N. (2001). Jenis-jenis teripang (Holothuroidea) di Perairan Kampung Auki Distrik Padaido Kabupaten Biak Numfor Papua. Jurnal Biologi Papua, 3(1), 24-31.

Schories, D., \& Kohlberg, G. (2016). Marine Wildlife Kong George Island Antartica. Dirk Schories Publications: Rostock.

Setiawan, R., Atmowidi, T., Widayati, K. A \& Purwati, P. (2018). Preferensi habitat spesies Ophiuroidea di Zona Intertidal Pantai Pancur Taman Nasional Alas Purwo. JurnalKelautan, 11(2), 151-166. https://doi.org/10.21107/jk.v11i2.4741.
Sugiyono. (2012). Metodologi Penelitian Kualitatif, Kuantitatif, dan $R$ \& D. Bumi Aksara: Bandung.

Suharsono. (2014). Biodiversitas Biota Laut Indonesia: Kekayaan Jenis, Sebaran, Kelimpahan, Manfaat dan Nilai Ekonomis. Puslit Oseanografi LIPI: Jakarta.

Supriharyono. (2007). Konservasi Ekosistem Sumber Daya Hayati. Pustaka Pelajar: Yogyakarta.

Triacha, Z. I. E. C., Meilisha, P. P., \& Rostikawati, R. T. (2021). Keanekaragaman Echinodermata di Pantai Cibuaya Ujung Genteng, Jawa Barat. Jurnal Ilmu Dasar, 22(1), 9-18.

Widiansyah, A. T., Munzil, M., \& Indriwati, S. E. (2016). Inventarisasi Jenis Arthropoda dan Echinodermata di Zona Pasang Surut Tipe Substrat Berbatu Pantai Gatra Kabupaten Malang. Jurnal Pendidikan: Teori, Penelitian dan Pengembangan, (7), 1417- 1420.

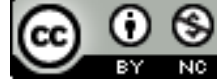

This work is licensed under a Creative Commons Attribution-NonCommercial 4.0 International License 